\title{
Corynespora cassiicola Isolates from Soybean in Alabama Detected with G143A Mutation in the Cytochrome b Gene
}

\author{
Marina Nunes Rondon and Kathy S. Lawrence ${ }^{\dagger}$ \\ Department of Entomology and Plant Pathology, Auburn University, Auburn, AL 36849
}

Accepted for publication 23 October 2019.

Keywords: fungicide resistance, cytb, mutation, quinone outside inhibitor

Corynespora cassiicola (Berk. \& M.A. Curtis) C.T. Wei is a widespread plant pathogenic fungus causing target necrotic spots on plant leaves, stems, and fruits, is worldwide on up to 400 plant species, and is known as Corynespora leaf spot or target spot on cotton and soybean. In the southeastern United States genetically distinct populations of $C$. cassiicola were found causing target spot epidemics on cotton and soybean (Sumabat et al. 2018).

Disease management has been a concern due to increasing occurrence of target spot (Godoy 2015). Severe disease symptoms and significant yield losses occur with this pathogen, especially during rainy seasons. Yield losses of 18 to $32 \%$ have been documented on soybeans in the United States (Godoy 2015). Fungicides have been a crucial tool in disease management; however, there are reported cases of $C$. cassiicola isolates from tomato, cucumber, and soybean resistant to systemic fungicides (Fungicide Resistance Action Committee [FRAC], https:// www.frac.info/publications).

C. cassiicola is considered a high-risk pathogen for development of fungicide resistance (FRAC 2019), and mutations associated with quinone outside inhibitor (QoI) resistance have been detected in the cytochrome $b(c y t b)$ gene based on three amino acid substitutions: G143A, F129L, and G137R (Duan et al. 2019). G143A mutation has been characterized for Cercospora sojina (Mathew et al. 2019) in the United States but not for $C$. cassiicola.

Fungicides are used to control cotton and soybean diseases; QoIresistant populations of $C$. cassiicola might be present in the United States. For this reason, the objective was to assess the occurrence of point mutations in the $c y t b$ gene associated with QoI resistance from Alabama isolates of $C$. cassiicola.

Symptomatic leaves were randomly collected from cotton and soybean plants (Fig. 1A to B) across Alabama in 2017/2018. Isolates of $C$. cassiicola were obtained by direct isolation on PDA containing $0.005 \%$ kanamycin. PDA plates were incubated at

${ }^{\dagger}$ Corresponding author: K. S. Lawrence; lawrekk@auburn.edu

Funding: This work was funded by Alabama Farmers Federation Soybean Committee (Hatch 015-2-14003).

The author(s) declare no conflict of interest.

This article is in the public domain and not copyrightable. It may be freely reprinted with customary crediting of the source. The American Phytopathological Society, 2019. room temperature $\left(25 \pm 2^{\circ} \mathrm{C}\right)$, and then pure colonies were obtained to establish the $C$. cassiicola Alabama collection (Fig. 1C to D). All isolates were identified as $C$. cassiicola based on conidiophore and conidia morphology (Fig. 1E to F) and internal transcribed spacer sequencing (ITS1/ITS4).

Total DNA was extracted using a ZR Fungal/Bacterial MiniPrep kit. To identify nucleotide point mutation on $c y t b$ gene, fragments were amplified from total DNA using PCR primers described by Duan et al. (2019). Purified PCR products were Sanger sequenced by Eurofins MWG Operon LLC (Louisville, KY), and nucleotide sequences were edited and aligned using BioEdit Alignment Editor (Tom Hall, Ibis Biosciences). Sequences were deposited in GenBank under accession numbers MN564884 to MN564895. QoIsensitive (C6-2) and QoI-resistant (ST-20S-1) sequences of $C$. cassiicola (Ishii et al. 2007) were included to illustrate the nucleotide point mutation.

A single DNA fragment (600 bp) was amplified using described primers, and based on cytb nucleotide sequences, four out of 12 isolates of $C$. cassiicola were found to have a mutation that replaces the codon for amino acid 143 from GGT to GCT, resulting in an amino acid change from glycine to alanine (G143A) (Fig. 2). These isolates originated from soybeans located in north (LIM14) and central (ELM04, ELM06, and ELM07) Alabama (Fig. 3). The G143A mutation was not found on isolates of $C$. cassiicola from cotton plants. No other point mutations on $c y t b$, such as F129L and G137R, were found in our isolates.

According to FRAC (2019), the short development of resistance to a different fungicide class by $C$. cassiicola on soybean is one example of a pathogen that must be classified as threatening. The amino acid change on cytb from glycine to alanine at position $143(\mathrm{G} 143 \mathrm{~A})$ is known to confer high levels of resistance to QoI fungicides, whereas F129L and G137R mutations are responsible for low to moderate levels of resistance (Duan et al. 2019).

QoI fungicides have a single-site mode of action and are extensively applied to manage multiple diseases in field crops. Given the high risk of $C$. cassiicola to develop fungicide resistance (Duan et al. 2019; Ishii et al. 2007), the management of fungicide resistance will be a major challenge. Knowing that field populations of $C$. cassiicola have mutations associated with QoI resistance, it will be necessary to monitor the spread of resistant isolates to manage resistance development. To the best of our knowledge, this study is the first to report G143A mutants in $C$. cassiicola from field populations from soybean in the United States. 


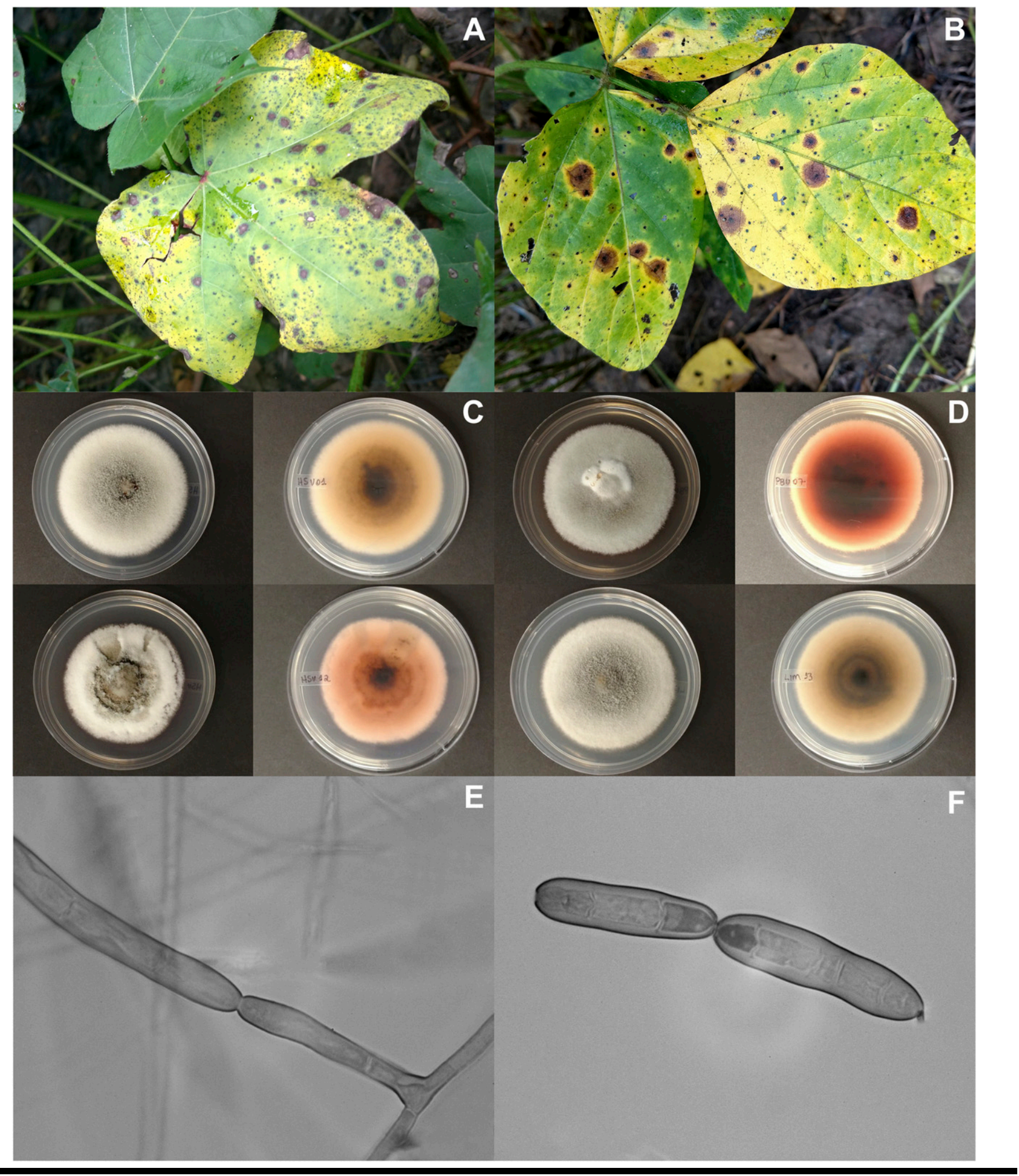

FIGURE 1

Target spot and its causal agent, Corynespora cassiicola. Disease symptoms on cotton (A) and soybean (B) leaves. Top and bottom of PDA plates with pure colonies of $C$. cassiicola obtained from cotton (C) and soybean (D) to establish a new collection from Alabama. Detail of the $C$. cassiicola conidiophore (E) and conidia (F) morphology. 


\begin{tabular}{|c|c|c|}
\hline & & $\begin{array}{c}\text { codon } \\
143\end{array}$ \\
\hline & C6-2 (Qol-sensitive) & GGTCAAATGTCCTTATGAGGTG CAACAGTTATTACT \\
\hline & BRW03 & GGTCAAATGTCCTTATGAGGTG CAACAGTTATTACT \\
\hline & MAC01 & GGTCAAATGTCCTTATGAGGTGCAACAGTTATTACT \\
\hline & FHP01 & GGTCAAATGTCCTTATGAGGTGCAACAGTTATTACT \\
\hline Cotton & FHP22 & GGTCAAATGTCCTTATGAGGTGCAACAGTTATTACT \\
\hline & HSV01 & G GT CAAATGTCCTTATGA G GTGCAACAGTTATTACT \\
\hline & HSV12 & GGTCAAATGTCCTTATGAGGTGCAACAGTTATTACT \\
\hline & LIM02 & GGTCAAATGTCCTTATGAGGTGCAACAGTTATTACT \\
\hline soybean & LIM13 & GGTCAAATGTCCTTATGAGGTGCAACAGTTATTACT \\
\hline & ST-20S-1 (Qol-resistant) & GGTCAAATGTCCTTATGA GCTGCAACAGTTATTACT \\
\hline & LIM14 & GGTCAAATGTCCTTATGAGCTGCAACAGTTATTACT \\
\hline & ELM04 & GGTCAAATGTCCTTATGAGCTGCAACAGTTATTACT \\
\hline Soybean & ELM06 & GGTCAAATGTCCTTATGAGCTGCAACAGTTATTACT \\
\hline & ELM07 & GGTCAAATGTCCTTATGAGCTGCAACAGTTATTACT \\
\hline & & $* * * * * * * * * * * * * * * * * * * \quad * * * * * * * * * * * * * * * *$ \\
\hline
\end{tabular}

\section{FIGURE 2}

Partial nucleotide sequences of the cytochrome $b$ gene of 12 isolates of Corynespora cassiicola plus two isolates used as a reference, Qol-sensitive (C6-2) and Qolresistant (ST-20S-1), from Ishii et al. (2007). Dark gray highlighted areas represent codon 143 and the amino acid substitution (G143A) that occurs as a result of the point mutation shown in bold (GGT $\rightarrow$ GCT).

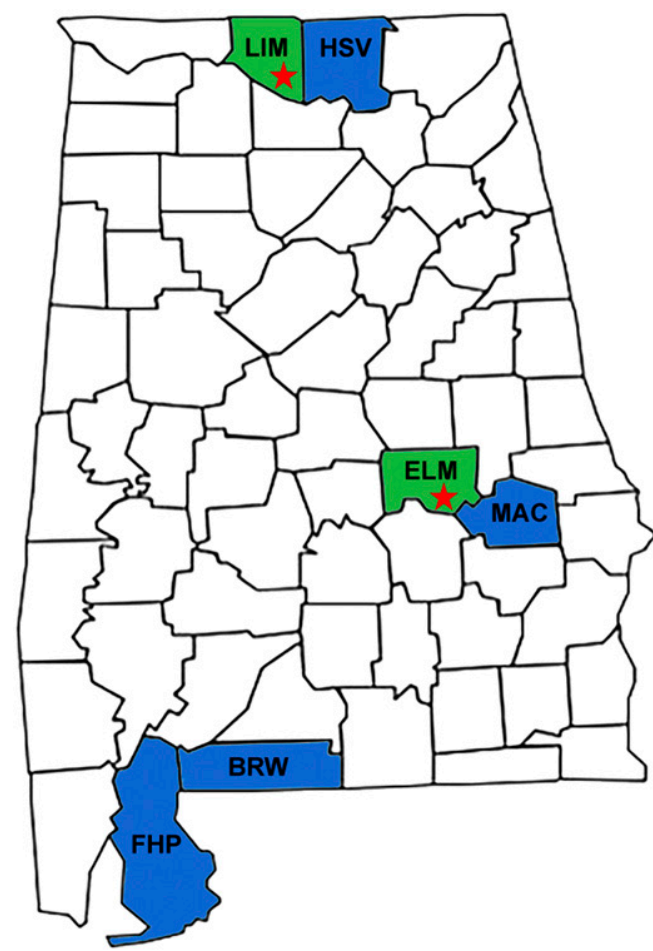

FIGURE 3

Distribution map of the Corynespora cassiicola isolates sampled from cotton (blue colored) and soybean (green colored) in Alabama, U.S.A. Abbreviations on the map represent the initial names of the isolates sampled. Red stars represent sampled locations where isolates were found with the G143A mutation.

\section{Literature Cited}

Duan, Y., Xin, W., Lu, F., Li, T., Li, M., Wu, J., Wang, J., and Zhou, M. 2019. Benzimidazole- and QoI-resistance in Corynespora cassiicola populations from greenhouse-cultivated cucumber: An emerging problem in China. Pestic. Biochem. Physiol. 153:95-105.

FRAC. 2019. Pathogen Risk List 2019. Fungicide Resistance Action Committee, CropLife International, Brussels, Belgium. Retrieved September 30, 2019, from https://www.frac.info/publications/downloads.

Godoy, C. V. 2015. Target spot. Pages 62-63 in: Compendium of Soybean Diseases and Pests. G. L. Hartman, J. C. Rupe, E. F. Sikora, L. L. Domier, J. A. Davis, and K. L. Steffey, eds. APS Press, St Paul, MN.

Ishii, H., Yano, K., Date, H., Furuta, A., Sagehashi, Y., Yamaguchi, T., Sugiyama, T., Nishimura, K., and Hasama, W. 2007. Molecular characterization and diagnosis of QoI resistance in cucumber and eggplant fungal pathogens. Phytopathology 97:1458-1466.

Mathew, F. M., Byamukama, E., Neves, D. L., and Bradley, C. A. 2019. Resistance to quinone outside inhibitor fungicides conferred by the G143A mutation in Cercospora sojina (causal agent of frogeye leaf spot) isolates from South Dakota soybean fields. Plant Health Prog. 20:104-105.

Sumabat, L. G., Kemerait, R. C., Jr., Kim, D. K., Mehta, Y. R., and Brewer, M. T. 2018. Clonality and geographic structure of host-specialized populations of Corynespora cassiicola causing emerging target spot epidemics in the southeastern United States. PLoS One 13:e0205849. 